\title{
Gênero, democracia e filosofia da ciência
}

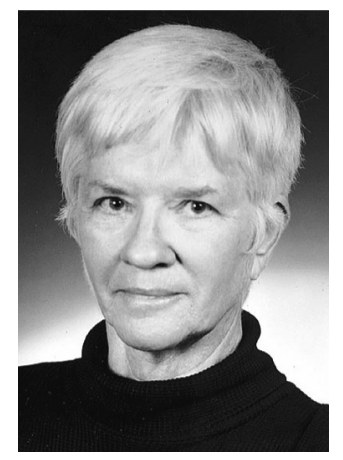

Sandra Harding

Graduate School of Education and Information Studies - University of California, Los Angeles, Estados Unidos

sharding@gseis.ucla.edu

\section{Resumo}

Epistemologias feministas e filosofias da ciência questionaram padrões convencionais de objetividade, racionalidade, "bom método" e "ciência real". Este texto enfoca os padrões mais fortes, reivindicados por feministas, para maximizar a objetividade e os desafios às filosofias e histórias da ciência convencionais resultantes do conhecimento de tradições da ciência e tecnologia não-ocidentais. As ciências e filosofias da ciência que quiserem promover o progresso e a justiça sociais não poderão fazê-lo se ignorarem esses desafios feitos por grupos localizados nas "periferias do Iluminismo".

\section{Palavras-chave}

Gênero, democracia, filosofia da ciência, epistemologias feministas, ciência não-ocidental

\section{Introdução}

Agora já se completaram três décadas que especialistas começaram a abordar as teorias e práticas da ciência e tecnologia (C\&T) por meio das diferentes perspectivas produzidas pelo movimento das mulheres nos Estados Unidos e na Europa. Esses especialistas se perguntam em que medida a C\&T discrimina os interesses das mulheres. Como uma estrutura social sexista na ciência e na sociedade produz os padrões de conhecimento e de ignorância das ciências modernas? O que pode ser feito para aumentar os efeitos democráticos dos projetos da C\&T? Especialmente na última década, as análises que partiram da vivência de mulheres pertencentes a minorias raciais e étnicas no Norte e de mulheres do Terceiro Mundo acrescentaram perspectivas diferentes a esses debates. ${ }^{1}$ Aqui, farei uma breve análise dos principais temas tratados nessa literatura e, em seguida, mais brevemente ainda, vou me ocupar de suas conseqüências para as teorias da democracia e para a filosofia da ciência.

\section{Questões de gênero}

Inicialmente, cinco tipos de questões chamaram atenção desses especialistas. ${ }^{2} \mathrm{O}$ espaço permite apenas uma rápida menção aos principais temas das quatro primeiras abordagens. Uma destas enfocou a ausência de igualdade de gênero na estrutura social das ciências naturais, da matemática e da engenharia. Historiadores descreveram como mulheres e gênero influenciaram as ciências européias e norte-americanas, e cientistas sociais documentaram os contínuos obstáculos com os quais as mulheres se depararam para atingir igualdade. 
Atualmente, mulheres têm tido amplo acesso ao estudo pré-profissional e profissional das ciências naturais, da matemática e da engenharia, ao ensino e a trabalhos em laboratórios, publicações em revistas especializadas em pesquisa, e ao quadro de membros de sociedades da C\&T. Todavia, quando se observa o mundo da $C \& T$, quanto mais alto o escalão, menos mulheres se encontram. Seja no Norte ou no Sul, poucas mulheres dirigem os mais prestigiosos laboratórios, são chefes de departamentos de ciências naturais, matemática e engenharia nas universidades ou ocupam posições do topo nas agências ou organizações políticas da C\&T internacionais. (HARDING et al., 1996; MIT, 1998; SCHIEBINGER, 1989; SCIENCE 1992, 1993, 1994)

A persistência dessa discriminação contra as mulheres levanta outras questões problemáticas. Mais questões sobre elas seriam abordadas pelos projetos da C\&T se houvesse mais mulheres elaborando políticas de C\&T no Norte e no Sul? Além disso, essa discriminação de gênero prejudica a objetividade das demandas de conhecimento e dos padrões de conhecimento produzidos pela C\&T? Deveríamos sempre nos preocupar quando aqueles que detêm o poder social, econômico e político e os que determinam o que consideram verdade são as mesmas pessoas?

Uma segunda abordagem enfocou os casos das aplicações de tecnologias da C\&T sexistas e androcêntricas. Tecnologias relativas à reprodução, habitação e local de trabalho, arquitetura e paisagismo urbano foram concebidas sem muita preocupação com a saúde, segurança e bem-estar das mulheres. Abordagens da tecnologia, feministas construtivistas, geraram análises esclarecedoras que foram obstruídas por concepções mais antigas de tecnologias como "máquinas e equipamentos" neutros culturalmente. Essas explicações mostram como os artefatos têm gênero. (COCKBURN, 1985; BERG et al., 1995; WAJCMAN, 1991). Especialistas indicaram como as chamadas práticas de desenvolvimento acrescentaram noções sexistas, do Norte, de culturas européias e norte-americanas, agências internacionais e corporações transnacionais às sociedades do Sul para reduzir a probabilidade de mulheres no Sul receberem benefícios de pesquisas da C\&T concebidas no Norte ou no Sul. Exemplos especialmente deploráveis dessa discriminação foram documentados no trabalho sobre saúde, agricultura, recursos naturais (energia, água etc.) e pesquisa sobre meio ambiente (BAIDOTTI et al., 1994).

Na terceira, resultados sexistas, racistas, imperialistas e "orientalistas" de pesquisas científicas nas áreas de biologia e ciências sociais justificaram imposições legais, econômicas e sociais que privam as mulheres de alguns direitos de cidadania. Ao mesmo tempo que esse tipo de pesquisa começou a florescer no século XIX, ainda tem êxito na sociobiologia e nas ciências sociais dominantes (FAUSTO-STERLING, 1994). Análises extremamente influentes emergiram de estudiosos e ativistas que trabalham com questões de gênero e desenvolvimento do chamado Terceiro Mundo (BRAIDOTTI et al., 1994; SMITH, 1999; VISVANATHAN et al., 1997).
Na quarta, o foco nos currículos e na pedagogia de ciências naturais, matemática e engenharia mudou a atenção das famosas deficiências das meninas e mulheres adultas para as deficiências evidenciadas dos currículos e da pedagogia da C\&T. Meninas e mulheres maduras tendem a ter diferentes estilos de aprendizado, de pesquisa e diferentes interesses na C\&T dos de seus irmãos. No Sul, os projetos de alfabetização da C\&T têm de lutar também contra as taxas de analfabetismo mais altas das mulheres, em algumas culturas, e contra a demanda de meninas e mulheres adultas para serviços domésticos (HARDING et al., 1996; ROSSER, 1986).

\section{Epistemologia feminista e filosofias da ciência}

Talvez mais potencialmente revolucionárias têm sido as críticas de filosofias da ciência convencionais. Essas filosofias articulam a "lógica" do que elas identificam como as práticas científicas mais desejáveis, baseadas em sua compreensão da história da ciência. Feministas se perguntaram: como os próprios padrões de objetividade, racionalidade, bom método e boa ciência refletiram desproporcionalmente as preocupações das instituições que usaram a C\&T como recurso para elaborar políticas constitucionais, de saúde, educacionais, militares e econômicas? Como seriam esses padrões se fossem concebidos para responder também aos interesses, medos e desejos das mulheres? Como seria a C\&T se as mulheres, do Sul e do Norte, fossem também seus sujeitos mais do que apenas seus freqüentemente objetos malcompreendidos? (BRAIDOTTI et al., 1994; HARDING, 1991; KELLER, 1984)

As respostas feministas mais interessantes a essas questões epistemológicas evitaram cuidadosamente rejeições inúteis de objetividade, racionalidade, bom método e da própria ciência. As mulheres necessitam mais objetividade, racionalidade, bom método e boa ciência para projetos que se originam em suas necessidades. Elas não necessitam as formas excessivamente estreitas dos que, há muito tempo, têm sido favorecidos nas filosofias da ciência.

Como exemplo, consideremos a importância dos modos padronizados de pensamento sobre objetividade para as feministas (HARDING, 1998). Maximizar a objetividade exigiu maximizar a neutralidade dos valores. De acordo com a visão convencional, é por meio dos métodos científicos, especificados nos projetos de pesquisa, que os valores sociais e os interesses que os pesquisadores inevitavelmente levam para seu trabalho podem ser identificados e eliminados. Essa abordagem certamente tem suas virtudes. Todavia, é evidente que ela só consegue alcançar uma forma fraca de objetividade, uma vez que muitas suposições sexistas e androcêntricas (sem falar das suposições baseadas em interesses e valores de classe, religião, cultura, nacionais, raciais e imperiais) moldaram, nos que foram declarados os projetos de pesquisa científica mais rigorosos, os resultados das pesquisas em C\&T, especialmente na biologia e nas ciências sociais. Como podem ser adequados os padrões convencionais de 
objetividade, se inúmeras vezes eles permitem descrições de inferioridade biológica e social das mulheres? ${ }^{3}$

Especialistas identificam três problemas desse tipo de padrão para maximizar a objetividade. Primeiro, importantes processos científicos ocorrem antes dos métodos científicos começarem e não são controlados por noções de método convencionais. Nesse "contexto da descoberta", condições problemáticas naturais ou sociais são identificadas como, por exemplo, a pobreza. Apenas o que é problemático é conceitualizado: "muitas bocas para se alimentar". Conceitos e hipóteses para conduzir pesquisas são formulados: "superpopulação"; "controle populacional"; "se a reprodução das mulheres for controlada, haverá menos bocas para alimentar”. Em seguida, é concebida a pesquisa para testar hipóteses. No caso aqui considerado, atualmente até as Nações Unidas reconhecem (desde a Reunião das Nações Unidas no Cairo em 1995 sobre população) que essa pesquisa supostamente objetiva não conseguiu identificar as suposições sexistas, racistas e classistas que moldaram muitas décadas de pesquisa sobre controle populacional. Em primeiro lugar, é a pobreza que causa o crescimento da população e não o contrário. Famílias pobres necessitam do trabalho e dos salários dos filhos para sobreviver e estes devem cuidar dos irmãos menores e, quando eles crescem, dos idosos, uma vez que os governos, rendas e riquezas herdadas sustentam as classes média e alta. Aumentar a educação das mulheres e, assim, sua renda possível constitui a única maneira mais eficaz de reduzir a fertilidade.

Assim, as abordagens feministas demandaram análises críticas sistemáticas do "contexto de descoberta" assim como do "contexto de justificação". Em primeiro lugar, pesquisas sobre a vida de mulheres, em vez de estruturas conceituais das instituições sociais dominantes e das disciplinas de pesquisa que lhes suprem de informações, podem gerar questões sobre "as práticas conceituais de poder” que não são acessíveis da perspectiva das instituições dominantes e de suas agendas de pesquisa (SMITH, 1990).

Uma segunda crítica da objetividade fraca é que sua maneira de identificar valores e interesses sociais consiste em repetir observações feitas por diferentes indivíduos ou grupos; os métodos para se obter resultados científicos devem ser repetidos. Ao mesmo tempo que essa exigência é eficaz para identificar valores e interesses que se diferem entre observadores individuais ou grupos de pesquisa, ela não identificará aqueles que são compartilhados. Opiniões sexistas e racistas não são invenções de indivíduos ou grupos de pesquisa; são suposições amplamente sustentadas por instituições e pela sociedade como um todo que, antes do surgimento de feminismos e anti-racismos, pareciam perfeitamente naturais para quase todo mundo.

No caso desses tipos de suposições profundas e difundidas, considera-se mais do que o uso de noções padronizadas de "bom método" para identificar valores e interesses distorcidos. Nesses casos, consideraram-se críticas políticas coletivas para dar visibilidade geral aos valores sociais e interesses que moldam as idéias sexistas e racistas. Mais uma vez, iniciar a pesquisa por estruturas conceituais diferentes das dominantes traz novas perspectivas para abordar as opiniões comuns de uma cultura. É claro que ninguém pode jamais ficar completamente fora de sua cultura. No entanto, simplesmente uma pequena liberdade relativa às opiniões prevalecentes pode proporcionar uma perspectiva crítica válida, como enfatizaram cientistas sociais ao relatarem a maior objetividade possível para quem está fora de um cultura.

Isso nos traz um terceiro problema relativo à objetividade fraca. Não é possível distinguir os tipos de valores e interesses que aumentam e os que atrasam o crescimento do conhecimento. Uma vez que a maximização da neutralidade de valores considerou-se a única maneira sempre razoável de tentar maximizar a objetividade, pareceu sem sentido levantar a questão se e como os valores e os interesses sociais podem, às vezes, de fato aumentar a objetividade. Adiantando, no momento, meu tópico final, podemos observar que aqui se encontra um importante desafio a ser abordado pelos pesquisadores que estiverem interessados na responsabilidade social da C\&T. Uma parte fundamental do desafio é conceitualizar como o que os pesquisadores observam é sempre dado tanto pela natureza quanto construído pela cultura - ou seja, evitar o naturalismo absoluto assim como o relativismo absoluto. Para colocar a questão de outra maneira, um tipo de realidade virtual é tudo aquilo que as ciências sempre mapearam para nós ou poderiam mapear.

Para começar a responder a esse desafio, podemos pensar como valores e interesses antidemocráticos bloqueiam o crescimento do conhecimento, uma vez que calam as mais vigorosas perspectivas críticas sobre modos de pensar antidemocráticos e outros modos dominantes. Valores e interesses a favor da democracia dão a essas perspectivas visibilidade geral e, assim, ampliam as oportunidades para maximizar a objetividade dos processos de pesquisa. Todavia, essa percepção é de fato aqui apenas um começo, pois precisamos pensar mais sobre o que, essencialmente, queremos dizer com valores e interesses democráticos (aqueles evidentes nas tendências correntes à "democratização" global, em que a desigualdade econômica é ignorada e até mesmo algumas vezes intencionalmente acelerada? Ver ROBINSON (1996) e a respeito de como, especificamente, os processos de pesquisa científicos e tecnológicos os desenvolvem ou os atrasam.

\section{Muitos feminismos, muitos interesses da C\&T}

A narrativa acima pode passar uma idéia de que há uma e apenas uma posição feminista sobre as questões da epistemologia e da filosofia da ciência. No entanto, isto não poderia acontecer e não acontece. Distintos feminismos surgiram nas "agendas públicas" durante os séculos XVIII e XIX na Europa e nos Estados Unidos. Estes basearam-se nas filosofias políticas - liberalismo, marxismo etc. - por meio das quais mulheres e homens fizeram reivindicações aos governos. Mary Wollstone- 
craft e John Stuart Mill começaram a pensar a partir da vivência das mulheres com quem tinham mais familiaridade. Tratava-se da vida das mulheres nas classes que tinham instrução, cujos interesses permaneceram fundamentais durante mais de dois séculos do Feminismo Liberal. É claro que hoje, quando a educação controlada pelo Estado continuamente aumenta a população das "classes com instrução", é possível argumentar que o Feminismo Liberal expandiu amplamente seus interesses e que seus adeptos vêm de um espectro econômico e político mais amplo do que o do século XVIII. Feministas liberais tiveram diferentes interesses na C\&T em comparação a outros grupos feministas como os dos feminismos marxistas e socialistas que surgiram no século XIX.

Assim, não é de se espantar que o pensamento sobre a C\&T do ponto de vista da vida de minorias raciais e étnicas no Norte e de mulheres no Sul também produza distintos interesses e temas. A narrativa acima sugere apenas algumas maneiras como os interesses dessa maioria de mulheres do mundo apareceram nas categorias críticas construídas para explicar grandes grupos de interesses da C\&T das mulheres do Norte. No entanto, começar a pensar fora dessas estruturas filosóficas liberais e marxistas também levanta questões inteiramente novas para a C\&T do Norte, feministas ou não (HARDING, 1993, 1998; HESS, 1995).

Apesar de tudo, as tentativas de acrescentar os interesses das mulheres às estruturas conceituais dominantes da biologia, sociologia, antropologia, economia, filosofia política e outras áreas revelaram, de forma consistente, que os próprios arcabouços eram resistentes a esses projetos aditivos. A vida das mulheres não podia ser objetivamente entendida através de estruturas que tinham complexos sistemas de noções e categorias elaborados para conceitualizar a biologia das mulheres como inferior e suas contribuições para as relações históricas e sociais como mínima ou até mesmo negativa. Mas, então, nem a vida dos homens poderia ser objetivamente compreendida através dessas estruturas. Se mulheres, sua natureza e suas atividades não são de fato inferiores mas meramente diferentes, então tampouco homens, sua natureza e atividades são superiores ou merecedores da marca distintiva do idealmente humano. As próprias estruturas conceituais foram questionadas meramente pelas tentativas de "acrescentar mulheres e misturar". Da mesma maneira, as tentativas de acrescentar a vivência da maioria das mulheres do mundo aos esquemas concebidos para explicar a vida de minorias relativamente privilegiadas no Norte moderno também mostraram as limitações daqueles arcabouços eurocêntricos para explicar objetivamente a vida de alguém.

O importante para mim, aqui, é que agora temos disponíveis múltiplas perspectivas teóricas feministas esclarecedoras para questionar a história e práticas da C\&T. E os feminismos multiculturais e pós-coloniais levantaram uma série de novas questões que colocaram desafios para as feministas do Norte assim como para as filosofias convencionais da C\&T. Aqui, apresento apenas três dessas questões.

\section{Questões filosóficas feministas multiculturais e pós-coloniais ${ }^{4}$}

Primeiro, precisamos novas histórias e geografias da distribuição, no passado e no presente, do conhecimento dos seres humanos pela C\&T. Não é mais razoável admitir que a ciência moderna ocidental seja a única capaz de contar uma história verdadeira sobre a organização da natureza. Hoje, novas histórias mostram a riqueza das tradições mais antigas chinesas, islâmicas e outras sul-asiáticas da C\&T e práticas inovadoras de tradições indígenas contemporâneas da C\&T em todo o mundo. Elas mostram a apropriação contínua dessas outras tradições de conhecimento pela C\&T do Norte. No sentido mais amplo da C\&T que essas novas descrições propiciam, as contribuições das mulheres para a história e para a acumulação atual de conhecimento humano ganham visibilidade. Além disso, essas narrativas revelam que, nos momentos marcados como progressivos nas histórias da ciência triunfalistas padronizadas, as mulheres e outros grupos subordinados, freqüentemente, perderam status sociais e recursos.

Em segundo lugar, os estudos da ciência multiculturais e pós-coloniais mostram como os padrões de objetividade, racionalidade, bom método, e mesmo boa ciência foram definidos não só distantes das qualidades e práticas associadas ao feminino, mas também distantes do primitivo. Os padrões filosóficos que orientam a C\&T ocidental moderna são padrões também de algumas formas características européias (e norte-americanas) de masculinidade. Eles não consideram os ideais humanos, mas apenas as formas historicamente específicas da masculinidade. Nos dois casos, esses padrões cortam a capacidade da C\&T moderna ocidental tanto de detectar estruturas conceituais e práticas válidas que outras culturas desenvolveram quanto de conseguir fazer uma avaliação objetiva da eficácia e das limitações reais dessa C\&T.

Tradições da C\&T não-ocidentais e de mulheres têm sido evitadas pelas filosofias da ciência nas áreas (entre outras) em que as mulheres estão inseridas em valores e interesses culturalmente locais e, portanto, não desinteressadas e objetivas transculturalmente. Todavia, essas tradições da C\&T proporcionaram conhecimentos sistemáticos sobre o mundo natural e o social que possibilitaram suas culturas sobreviverem e prosperarem. Por outro lado, o desinteresse da C\&T ocidental tornou-a útil para os atores mais poderosos da economia política global atual cada vez mais desigual, sem falar de uma longa história de outros projetos militaristas, lucrativos e antidemocráticos. Enquanto não estivermos preparados para compreender como a ética e a política moldam a boa ciência e não apenas a "ciência ruim", não conseguiremos limitar os caminhos que levam a C\&T a continuar servindo aos interesses do poder político e econômico.

Finalmente, como as duas primeiras questões indicadas, esses estudos da C\&T feministas, multiculturais e pós-coloniais, mostram como todos os sistemas de conhecimento, inclusive a C\&T moderna ocidental, são historicamente diferentes, ou "locais", de maneira significativa. Esses estudos quebram narrativas padronizadas 
triunfalistas das contribuições da C\&T moderna ocidental para o progresso humano. Uma vez que diferentes culturas, ou mulheres e homens de uma cultura se interagem diferentemente com os ambientes naturais e sociais, têm interesses diversos, utilizam recursos de argumentação diferenciados e organizam distintamente a produção de conhecimento, tendem a desenvolver uma grande e variada quantidade de conhecimento sistemático e de ignorância sistemática. Por exemplo, aquelas que são designadas a cuidar de crianças e os que são designados a cuidar de motocicletas (para ser fiel aos estereótipos) desenvolverão distintos padrões de conhecimento e de ignorância de relações naturais e sociais. Assim, mulheres e homens em todas as profissões e diferentes culturas, em qualquer lugar do mundo, à medida que se ocupam de diferentes tipos de atividade, desenvolverão e manterão distintos padrões de conhecimento (e de ignorância). Além disso, todas essas são "ciências modernas" uma vez que são continuamente avaliadas sobre a possibilidade de seus usuários interagirem efetivamente com ambientes modificados e com informações e modos de pensamento recentemente vindos de outras pessoas e culturas.

Essas questões desafiam os remanescentes da velha tese de unidade da ciência, segundo a qual há um mundo, uma "verdade" (explicação verdadeira) sobre ele, e uma única ciência (diferente historicamente, embora transcultural) essencialmente capaz de produzir aquela explicação verdadeira. Poucos que hoje refletem sobre a imensa diversidade de ontologias, epistemologias, e métodos que caracterizam as chamadas ciências modernas, sem mencionar as muitas outras tradições da C\&T que contribuíram para o acúmulo do conhecimento humano, admitiriam essa tese de unidade da ciência em suas formas mais restritivas (Galison et al., 1996). No entanto, a maioria de nós detém suposições de unidade que dificultam avaliar os estudos multiculturais e póscoloniais disponíveis da C\&T científicos, filosóficos, e sobre oportunidades feministas pró-democráticas. Como seria uma teoria do conhecimento humano que se construísse com base nas percepções desses movimentos contemporâneos característicos?

\section{Notas}

1. Muitos termos fundamentais dessas discussões, tais como Terceiro Mundo, pós-colonialismo, desenvolvimento, feminismo e a própria palavra ciência são questionados. Por isso devem permanecer como os horizontes de nossa compreensão sobre como a C\&T funciona nas relações sociais locais e globais que continuam a se expandir.

2. Analisei essas questões em vários lugares. Ver, por exemplo, HARDING (1991).

3. Existe atualmente uma ampla literatura que documenta essas afirmações feitas pela área de biologia e pelas ciências sociais. No que se refere à biologia, FAUSTO-STERLING (1994) é um bom trabalho para se começar.

4. Estudos da C\&T multiculturais e pós-coloniais com seus diversos componentes feministas começaram a ter visibilidade internacional desde meados da década de
1980. Temas centrais e fontes dessa literatura podem ser encontrados em BRAIDOTTI et al., 1994; HARDING, 1998; e HESS, 1995.

\section{Referências bibliográficas}

BERG, A-J.; MERETE L. Feminism and Constructivism: Do Artifacts Have Gender? Science, Technology, and Human Values, v.20 n.3, p.332-35 1, 1995.

BRAIDOTTI, R. et al. Women, the environment, and sustainable development. Atlantic Highlands, N.J.: Zed, 1994.

COCKBURN, C. Machinery of dominance: women, men, and technical know-how. London: Pluto Press, 1985.

FAUSTO-STERLING, A. Myths of gender: biological theories about women and men. New York: Basic Books, 1994.

GALISON, P.; STUMP, D. (Eds.) The Disunity of Science. Stanford: Stanford University Press, 1996.

HARDING, S. Feminism Confronts the Sciences: Reform and Transformation. In: Whose Science? Whose Knowledge? Thinking From Women's Lives. Cap. 2. Ithaca: Cornell University Press, 1991.

HARDING, S. (Ed.). The 'Racial' Economy of Science: Toward a Democratic Future. Bloomington: Indiana University Press, 1993.

HARDING, S. Is science multicultural? Post-colonialisms, Feminisms, and Epistemologies. Bloomington: Indiana University Press, 1998.

HARDING, S.; MCGREGOR, E. "The Gender Dimension of Science and Technology," UNESCO World Science Report 1996. Paris: UNESCO, 1996.

HESS, D. Science and technology in a multicultural world: the cultural politics of facts and artifacts. New York: Columbia University Press, 1995

KELLER, E.F. Reflections on gender and science. New Haven: Yale University Press, 1984.

MIT. “Women Scientists at MIT.” A Report, 1998.

ROBINSON, W.I. Promoting polyarchy: globalization, U.S. intervention, and hegemony. New York: Cambridge University Press, 1996.

ROSSER, S. Teaching science and health from a feminist perspective. Oxford: Pergamon Press, 1986.

SCHIEBINGER, L. The mind has no sex? Women in the origins of modern science. Cambridge: Harvard University Press, 1989.

SCIENCE. Women in science. v. 255, s.p, 1992; v.260, p.383-430, 1993; v.263, p.1467-93, 1994.

SMITH, D.E. The conceptual practices of power: a feminist sociology of knowledge. Boston: Northeastern University Press, 1990. 
SMITH, L.T. Decolonizing methodologies: research and indigenous peopes. New York: Zed Books, 1999.

VISVANATHAN, N. et al. (Eds.) The women, gender and development reader. London: Zed Books, 1997.
WAJCMAN, J. Feminism confronts technology. University Park: Pennsylvania State University, 1991

\section{Sobre a autora}

\section{Sandra Harding}

Filósofa. Atualmente professora de Educação e Estudos da Mulher na University of California (UCLA) em Los Angeles nos Estados Unidos. Lecionou por duas décadas na University of Delaware antes de se juntar à UCLA em 1996. Desde então, dirigiu o Center for the Study of Women da UCLA de 1995-2000, e co-editou a revista "Signs: Journal of Women in Culture and Society" de 2000 a 2005. É autora e editora de mais de quinze livros e revistas especiais incluindo: Science and Social Inequality: Feminist and Postcolonial Issues (2006); The Feminist Standpoint Theory Reader (2004); Science and Other Cultures: Issues in Philosophies of Science and Technology, co-editado com Robert Figueroa (2003); Is Science Multicultural? Postcolonialisms, Feminisms, and Epistemologies (1998); The Science Question in Feminism (1986). É professora visitante na University of Amsterdam, na University of Costa Rica, no Swiss Federal Institute of Technology, e no Asian Institute of Technology. Além disso, foi consultora de diversas organizações das Nações Unidas incluindo a Organização Mundial de Saúde, UNESCO e o Fundo de Desenvolvimento das Nações Unidas para a Mulher (UNIFEM), e a Comissão das Nações Unidas em Ciência e Tecnologia para o Desenvolvimento. Atualmente está escrevendo um livro sobre gênero, ciência e modernidade. 